\title{
MODELLING OF METAL FLOW, THERMAL AND MICROSTRUCTURAL EVALUTIONS DURING MULTIPASS HOT BAR ROLLING
}

\author{
M. Abo-Elkhier \\ Department of Production Engineering and Mechanical Design, \\ Faculty of Engineering, Menoufia University, \\ Shebin El-kom, Egypt, 32511
}

\begin{abstract}
A three-dimensional finite element model for analysis of metal flow, thermal and microstructural evolutions during hot bar rolling is presented. The heat transfer coefficients at the bar surface are allowed to vary as it is assumed that the bar is either in the air or in contact with the rolls. The microstructural model includes the possibility of both dynamic and static recrystallizations and grain growth during interpass time. Hot rolling process of a square bar in square-diamond-square-square pass sequence is analyzed. Data of temperature, strain and strain-rate distributions are used to compute the microstructural evolution in each pass. The predictions of the model are validated by comparing the calculated results with experimental data available in the literature
\end{abstract}

\section{KEYWORDS:}

Finite element modelling, Hot bar rolling, Temperature distribution, Microstructural evolution, Numerical analysis.

\section{INTRODUCTION}

Modelling of hot rolling processes has become a very important field of study for academic and industrial researchers since it gives new insight into the physical behaviour of the material. The most important feature in the modelling is the thermal evolution since the flow stress of the material depends on the strain, strain-rate and temperature whilst, microstructural evolution is sensitive to temperature and strain-rate. Therefore, the important

Manuscript received from Dr. M.Abo-Elkhier

Accepted on : $24 / 6 / 2001$

Engineering Research Journal Vol 24,No 3, 2001 Minufiya University, Faculty of Engineering, Shebien El-Kom, Egypt, ISSN 1110-1180 
task now is to combine the efforts in the field of plastic flow, heat transfer and microstructural evolution to produce integrated model for the final microstructure and material properties predictions. Several investigations have been carried out for the finite element modelling of thermo-mechanical events and microstructural evolution in hot strip or plate rolling [1-6]. In shape rolling, however, the improvement in modelling is very limited due to the complicated nature of deformation, thermal and microstructural evolutions. Komori [7] proposed a model for plastic flow and temperature distribution only, in which the plastic flow is analyzed using threedimensional finite element whilst the temperature distribution is calculated using combination of finite element and finite difference. As far as the author is aware, only an integrated model has been developed by Glowaski et al. [8] for the plastic flow, heat transfer and microstructural evolution during shape rolling. However, they applied the general plane strain principle in the rolling direction which restricts the deformation pattern considerably.

The prime objective of the present investigation is to present a thermomechanical and microstructural finite element model. The developed finite element program FESHRL [9] has been enhanced with the thermal as well as the microstructural models. The heat transfer coefficients at the bar surface are allowed to vary as it is assumed that the bar is either in the air or in contact with the rolls. Deformation, thermal and microstructural evolutions during hot rolling of low carbon steel bar of square cross-section of $16 \times 16$ $\mathrm{mm}$ to a square of $10 \times 10 \mathrm{~mm}$ in square-diamond-square-square pass sequence are simulated. The predictions of the temperature histories and grain size are compared with those recorded and measured experimentally. $[10,11]$

\section{FINITE ELEMENT MODELLING}

The model consists of three parts : the mechanical part, the thermal part and the microstructurral evolution part. In the following, the three parts will be described briefly.

\subsection{Mechanical Part}

The mechanical part is based on the incremental updated Lagrangian formulation as presented in ref. [9]. The formulation takes into account the geometrical (large strain) and the material nonlinearities. The material behaviour at elevated temperature is assumed to be elasto-viscoplastic. The yield strength of the steel is assumed to be a function of carbon content, strain, strain-rate and finally the temperature.

Owing to the symmetry of the rolling process, only one-quarter of the bar is modelled in each pass. Although the program FESHRL is structured in a general manner, a subroutine is developed to determine the contact between the bar and the roll. In each time increment, the surface nodes are checked to find out which get in contact with the roll or separate from it. 


\subsection{Thermal Part}

Heat transfer in the deformation zone is simulated by the finite element solution of the general heat balance equation as follows:

$$
\nabla^{\mathrm{T}} \mathbf{k}_{\mathrm{b}} \nabla \mathrm{T}+\mathrm{Q}_{\mathrm{p}}=\rho \mathrm{c}_{\mathrm{p}} \frac{\partial \mathrm{T}}{\partial \mathrm{t}}
$$

where $\nabla$ is the Laplacian, $k_{b}$ is the heat conduction coefficient, $T$ is the temperature, $\rho$ is the material density, $c_{p}$ designates the specific heat of the material, and finally $Q_{p}$ is the rate of heat generation due to plastic deformation.

The heat flux per unit area through the bar/roll contact surface is calculated as:

$$
\alpha\left(\mathrm{T}_{\mathrm{bar}}-\mathrm{T}_{\mathrm{roll}}\right)=\mathrm{k}_{\mathrm{r}} \frac{\partial \mathrm{T}}{\partial \mathrm{r}}
$$

where $\alpha$ is the heat transfer coefficient and $\mathrm{k}_{\mathrm{r}}$ is the thermal conductivity of the roll material. The heat transfer coefficient was measured experimentally during hot rolling of steel under the same laboratory conditions as 13 $\mathrm{kW} / \mathrm{m}^{2} \mathrm{~K}$ [12].

In the region between two rolling passes, two type of heat losses; radiation and convection from the bar to the air are considered as follows:

$$
Q=\xi S A\left(T_{b a r}^{4}-T_{a m b}^{4}\right)+h_{c o n} A\left(T_{b a r}-T_{a m b}\right)
$$

Where $\xi$ is the emissivity of the steel, $S$ is Stefan-Boltzman constant $\left(5.6699 \times 10^{-8} \mathrm{~W} / \mathrm{m}^{2} \mathrm{~K}^{4}\right)$ and $\mathrm{h}_{\mathrm{con}}$ is the convective heat transfer coefficient.

\subsection{Microstructural Part}

The algorithm employed here to microstructural evolution determines weather dynamic recrytallization is occurred within each pass or not. If so, the transformed fraction and the resulting grain size are calculated. The critical strain for the onset of the dynamic recrytallization is calculated as follows:

$$
\epsilon_{\mathrm{dyn}}=\mathbf{a d} \mathrm{d}_{0}^{\mathrm{b}} \mathrm{Z}^{\mathrm{c}}
$$

Where $a, b$ and $c$ are empirical constants depending on the chemical composition of the steel, $d_{0}$ is the initial grain size and $Z$ is the ZenerHollomon parameter. The constants $\mathrm{a}, \mathrm{b}$ and $\mathrm{c}$ are determined experimentally for the used low carbon steel as $1.13 \times 10^{-6}, 1.404$ and 0.202 , respectively [11]. The Zener-Hollomon parameter is defined as follows:

$$
\mathrm{Z}=\dot{\varepsilon} \exp \left(\mathrm{Q}_{\text {act }} / \mathrm{RT}\right)
$$


Where $\dot{\varepsilon}$ is the strain-rate, $\mathrm{R}$ is the gas constant and finally $\mathrm{Q}_{\mathrm{act}}$ is the activation energy for deformation, which is assumed to be independent of testing conditions and initial microstructure and depends only on the chemical composition. In case of low carbon steel, $Q_{\text {act }}$ can be calculated as [13]:

$$
\mathrm{Q}_{\mathrm{act}}=282.7+92.4(\% \mathrm{C})+6.57(\% \mathrm{Mn}+\% \mathrm{Si})
$$

where the energy is expressed in $\mathrm{kJ} / \mathrm{mol}$.

The dynamically recrystallized grain size $d_{d y n}$ is calculated as follows :

$$
\mathrm{d}_{\mathrm{dyn}}=\mathrm{pZ}
$$

where $p$ and $m$ take the value $2.6 \times 10^{4}$ and -0.23 , respectively. The recystillized fraction is calculated using Avrami equation as follows :

$$
\begin{aligned}
& \mathrm{X}=1-\exp \left[-0.693\left(\mathrm{t} / \mathrm{t}_{0.5}\right)^{\mathrm{r}}\right] \\
& \mathrm{t}_{0.5}=\mathrm{K}_{\mathrm{md}} \mathrm{Z}^{\mathrm{m}} \exp \left(\mathrm{Q}_{\mathrm{md}} / \mathrm{RT}\right)
\end{aligned}
$$

The exponent $r$ may be regarded as a material constant which for C-Mn steels varies between 1.5 and $2, t$ is the elapsed time and $t_{0.5}$ is the time required for $50 \%$ recrystallization The constants $\mathrm{K}_{\mathrm{md}}$ and $\mathrm{m}$ take the vales 0.53 and -0.8 , and $\mathrm{Qmd}_{\mathrm{md}}$ is assumed to be $75 \%$ of the numerical value of $\mathrm{Q}_{\text {act }}$ [2].

After deformation, static recovery and recrystallization take place. The grain size resulting from this process can be calculated as follows:

$$
\mathrm{d}_{\text {static }}=\epsilon^{-0.67} \mathrm{~d}_{0}^{-0.67}
$$

where $\epsilon$ is the accumulated strain during the pass.

After the recrytallization has been completed, the grains may grow during interpass time. The resulting grain diameter may be calculated as:

$$
d^{m}=d_{\text {rec. }}^{m}+k_{1} t \exp \left(-Q_{g g} / R T\right)
$$

where the values of the constants $m$ and $k_{1}$ are 6 and $1.8 \times 10^{26}$, respectively, and the activation energy $\mathrm{Q}_{\mathrm{gg}}$ is set equals to $437 \mathrm{~kJ} / \mathrm{mol}$ [2].

\section{RESULTS AND DISCUSSIONS}

\subsection{Rolling Conditions}

Figure 1 shows the dimensions of the pass schedule (square-diamondsquare-square) grooved in two rolls of $135 \mathrm{~mm}$ maximum diameter and 200 mm width made from $\mathrm{H} 13$ tool steel. Upper and lower rolls are closed together to make a rolling clearance of $3 \mathrm{~mm}$. Low carbon steel bar of square cross-section of $16 \times 16 \mathrm{~mm}$ and length of $80 \mathrm{~mm}$ is rolled to a square of $10 \times 10 \mathrm{~mm}$. The chemical composition of the low carbon steel by weight is 
given in Table (1). The grain size at the entrance of the first pass equals 128 $\mu \mathrm{m}[10,11]$.

Table.1 Chemical composition of the rolled low carbon steel (w\%)

\begin{tabular}{|c|c|c|c|c|c|}
\hline $\mathrm{C}$ & $\mathrm{Mn}$ & $\mathrm{Si}$ & $\mathrm{S}$ & $\mathrm{P}$ & $\mathrm{Fe}$ \\
\hline 0.19 & 0.72 & 0.05 & 0.007 & 0.009 & rest \\
\hline
\end{tabular}

Figure $2 \mathrm{a}, \mathrm{b}, \mathrm{c}$ and $\mathrm{d}$ shows the finite element mesh with the contact boundary between the roll and the bar in each pass. It is found that in the first and last passes (square-to-square), the contact started near the bottom whilst in case of the second pass (square-to diamond) and the third one (diamondto-square), the contact began at the top. It should be noticed that the bar is turned by $90^{\circ}$ after each pas

It is obvious that, employing the finite element technique in the analysis results in a large amount of data. In the following, however, discussion of thermal and microstructural evolutions results is only presented.

\subsection{Thermal Model Results}

The temperature histories of three points, (the central point $\mathrm{A}$, the mean height $B$ and the surface point $C$ ) are presented in Fig. 3 as well as those recorded experimentally using thermocouples embedded in the bar [10,11]. The thermocouple $\mathrm{C}$ is placed as close to the surface as possible without causing fracture. The roll speed is $10 \mathrm{rpm}$, leading to a roll velocity of 70.69 $\mathrm{mm} / \mathrm{sec}$. Reasonable agreements are shown between the obtained temperature histories and the recorded ones. The temperature of the bar shows small increases at point $A$ due to plastic deformation inside the deformation zones and fairy large drops at point $\mathrm{C}$ due to the contact with the roll. The temperature drops in the second and third passes are relatively large compared to that of the first one due to long contact time in both cases. There are some discrepancies in the second and third passes which may be due to random development of oxide layer on the bar surface.

In all passes, the hot center acts as a heat source after the exit plane and the bar surface temperature increased.

The thermal gradient within the cross-section of the bar can be obtained at any point along the deformation zone. Temperature contours across the crosssection at the exit plane for each pass are shown in Fig. 4. a, b, c, and d. The temperature gradients in the first three passes is large, whilst that for the fourth pass is rather small. This phenomena together with the strain and the strain-rate distributions affects the distribution of the grain size across the cross section. 


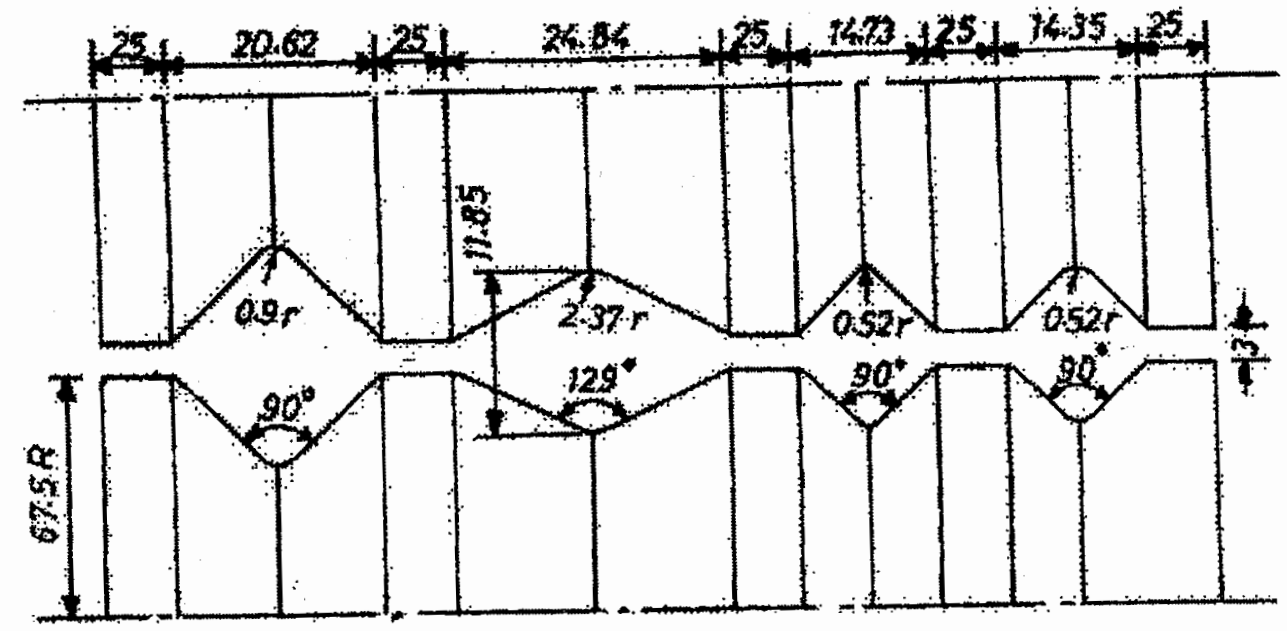

Fig.1. Detailed dimensions of the four passes (mm).

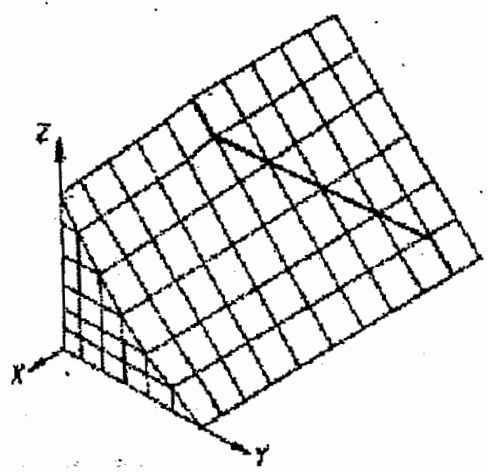

a) square-to-square

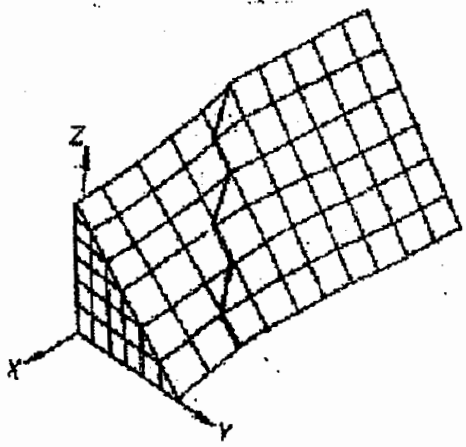

a) diamond-to-square :

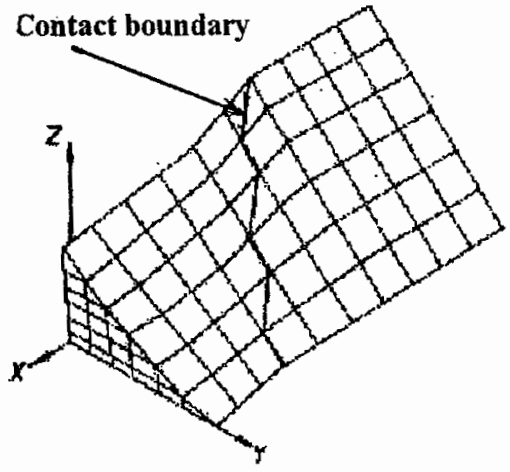

b) square-to-diamond

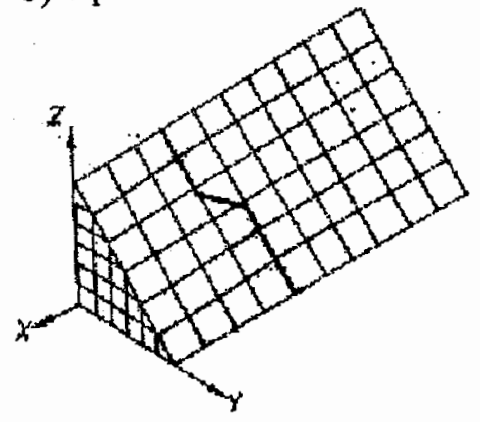

d) square-to-square

Fig.2. Finite Element meshes of the four passes with contact boundaries. 


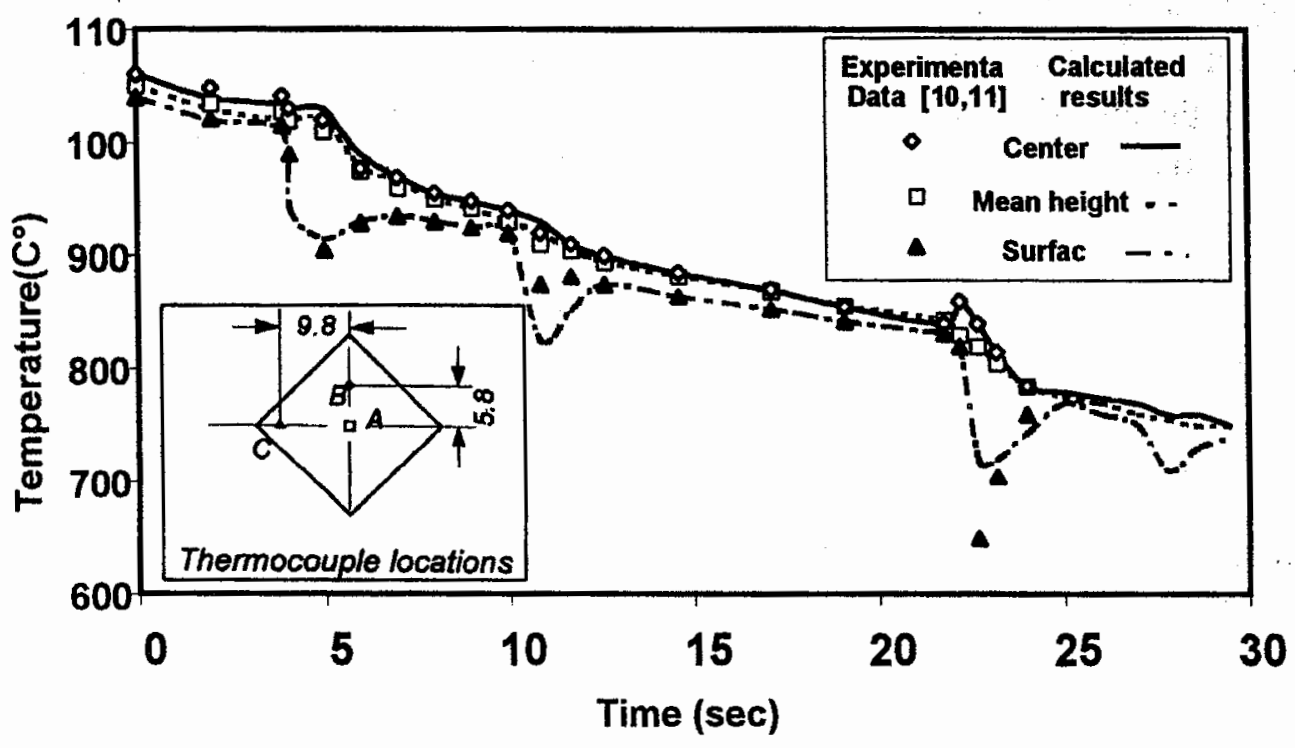

Fig.3. Temperature history of the rolled bar during four pass sequences

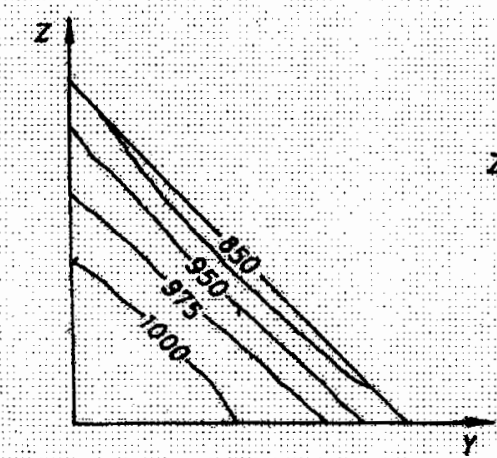

a) Square-to-square

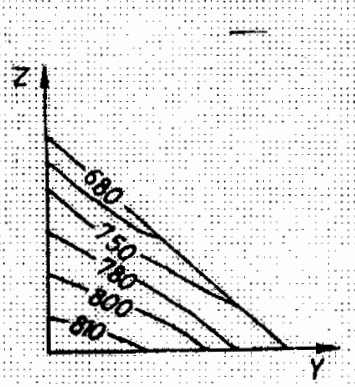

c) Diamond-to-square

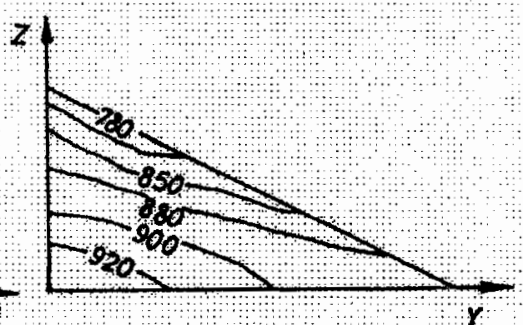

b) Square-to-diamond

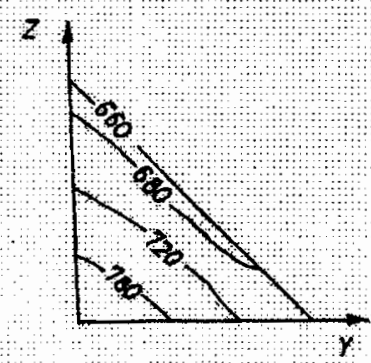

d) square-to-square

Fig.4. Temperature contours across the cross-section. $\left(\mathrm{C}^{\circ}\right)$

\section{3-3 Microstructural Model Results}

Figure (5) compares the calculated and the measured grain diameters in the bar center at the exit plane. The roll speed in this case is $15 \mathrm{rpm}$ (roll velocity of $106.03 \mathrm{~mm} / \mathrm{sec}$ ). Good agreement is shown between the two sets of results. The microstructural evolutions at the three points $\mathrm{A}, \mathrm{B}$ and $\mathrm{C}$ are 
depicted in Fig. (6). It is found that the grain size varies from $83 \mu \mathrm{m}$ at the center to $20 \mu \mathrm{m}$ at the surface in the first pass and a continuous decreases in it as the material rolled through the passes and finishes with small difference of $6 \mu \mathrm{m}$ in the fourth pass. The grain growth during interpass time is noticeable at high temperature, whilst it is insignificant as the material cools down.

The grain size distributions at the exit plane for the four passes are shown in Fig. 7 a, b, c, and d. Large strain rates near the surface in the first three rough rolling passes, initiate dynamic recrystallization which produce significant refinements in grain size. Whilst in the finishing pass (fourth pass) the dynamic and static recrystallizations are small. Relatively long interpass time and high temperature result in some grain growth but due to recrystallization, an overall decreasing tendency is observed.

\section{4-CONCLUSIONS}

A finite element model for the analysis of metal flow, thermal and microstructural evolutions during hot shape rolling process is presented. The finite element computer program FESHRL [9] has been enhanced with the thermal and microstructural models. Hot rolling process of a square bar of low carbon steel in square-diamond-square-square pass sequence is analyzed. The comparison between the temperature histories and the grain size with those recorded and measured experimentally is good. This demonstrate that the finite element simulation of hot bar rolling proceess can be used to predict the resulting microstructure with reasonable accuracy.

It is found that in rough rolling passes, large strain-rates and accumulated strains together with high deformation temperature result in significant refinements in grain size which has beneficial effect on the properties of the rolled product. On the other hand, the microstructural evolution is minor in the finishing passes.

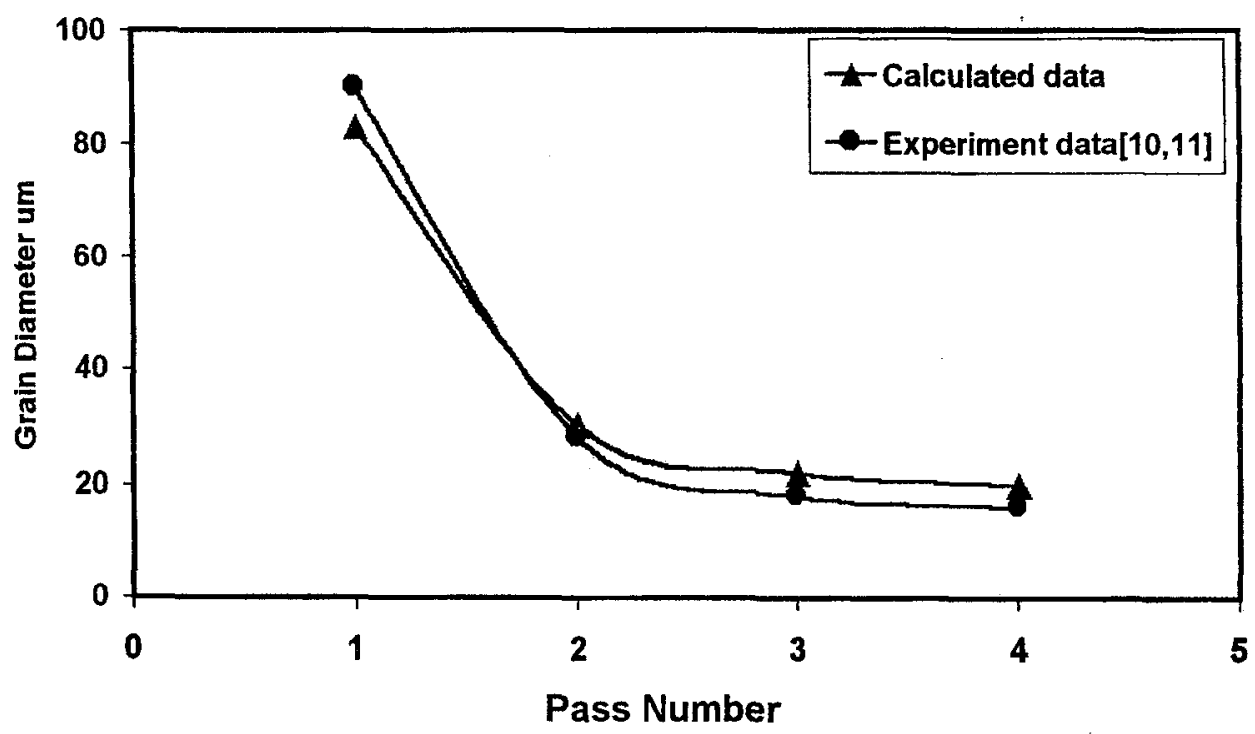

Fig.5. The Calculated and the measured recrystallized grain diameter for four rolling passes at the bar centre 


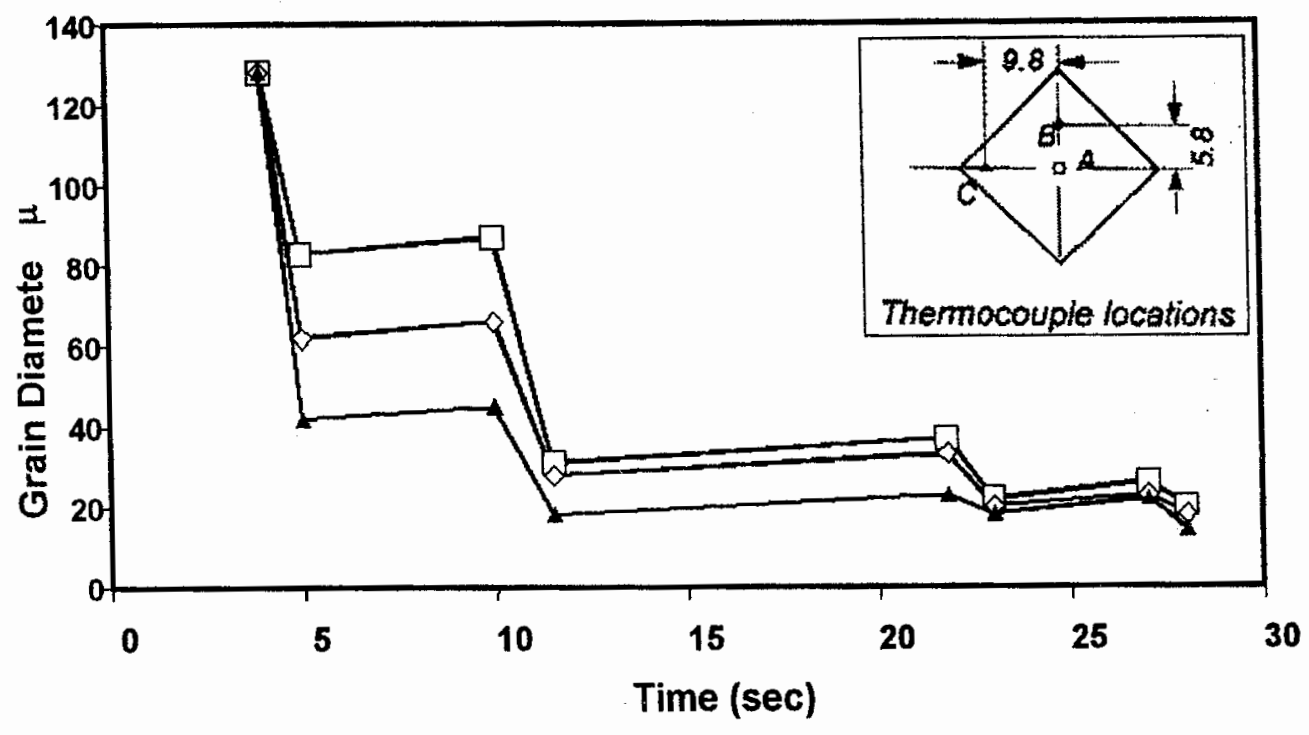

Fig. 6. The microstructural evolutions at the three points A, B and C

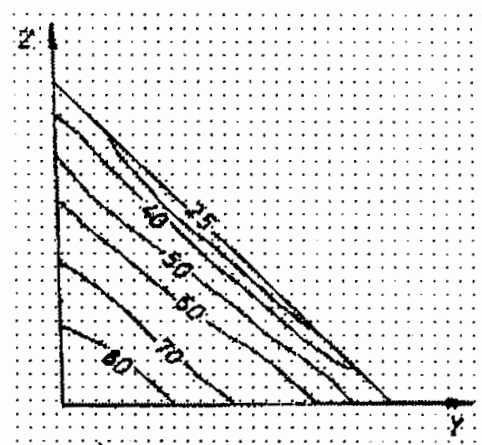

a) square-to-square

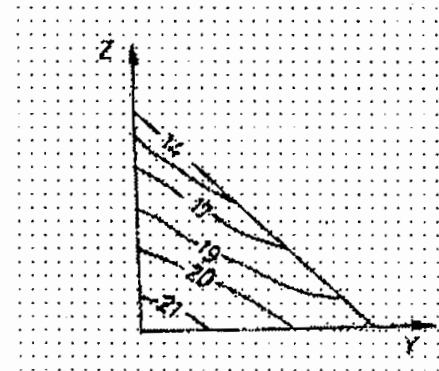

c) diamond-to-square a) squaretto diamond
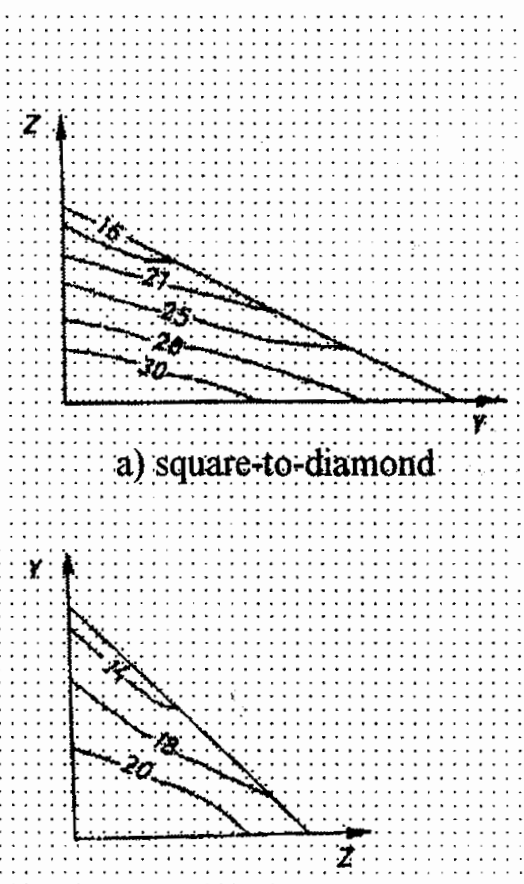

d) square-to-square

Fig.7. Grain size distributions across the cross-section $(\mu \mathrm{m})$

\section{REFERENCES}

1.Chin, B., Nemes J.A. and Yue S., "Influence of strain distribution on microstructure evoution during rod-rolling", Int. J. Mech. Sci., Vol. 41, pp. 1111-1131, 1999.

2.Colas, R. "Mathematical modelling of hot rolling steel strip", Mat. Sci. and Tech., Vol. 14, pp. 388-393, 1998. 
3.Kadzierski, Z. Packo, M, Skolyszewskii, A. Zielinska A.and Kusiak, H.“ Validation of thermomechanical and microstructural models for nobium steels in hot rolling-drawing , J. of Mat. Proc. Tech., Vol. 60, pp 603608, 1996.

4.Biglou J.and. Lenard, J.G,." A study of dynamic recrystallizatization during hot rolling of miicroaloyed steels", Manufacturing Tech., Vol. 45, pp 227-230, 1996.

5.Laasraoui A. and Jonas J.J.," Prediction of temperature distribution, flow stress and microstructure during the multi-pass hot rolling of steel plate and strip", ISIJ International, Vol. 31, pp 95-105, 1991

6.Pietrzyk M., Kusiak H., Korhonen A.S and Mainenn M," "Thermal, mechanical and microstructural model for reverse hot rolling", Scandian J. of Metallurgy, Vol.. 21, pp 229-232, 1992.

7.Komori, K." Simulation of deformation and temperature in multi-pas calibar rolling", J. of Mat. Proc. Tech., Vol. 71, pp 329-336, 1997

8.Glowacki M., Kuziak R., Malinowki Z. and Pietrzyk M., “ Modelling of heat transfer, plastic flow and microstructural evolution during shape rolling", J. of Mat. Proc. Tech., Vol.53, pp 159-166, 1995

9.Abo-Elkhier M., “ Modelling of shape rolling using three-dimensional finite element technique ", Proc. Of 7th Cairo Int. Conf. on Mechanical design \& Prod. (MDP7), pp 293-302 2000.

10.Said A.H, Lenard J.G., Ragab A.R. and Abo-Elkhier M., "Evolution of the microstructure in hot bar rolling", Proc. of 6th Cairo Int. Conf. on Mech. Design \& Prod. (MDP6), pp 375-387, 1996

11. Said , A.H., " Experimental investigation and analysis of hot section rolling " , Ph.D. thesis , Dept of Prod. Eng. \& Mech. Desgin, faculty of Engenegring Menoufia University, 1996.

12-Pietrzyk, $M$ and Lenard, J.G., " Thermomechanical modelling of the hot bar rolling process" Spring Vellage, 1992.

13.. Colas R.,", A model for the hot deforrmation of low carbon steel ", J. of Mat Proc.Tech., Vol. 62, pp 180-184, 1996. 


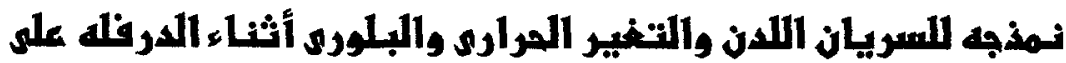 السافنز اللعضو فئ ومرات متعددة
}

\author{
محمود أبو الميّي \\ قسم هندسة الإتتاج والتصميم الميكانيكى التئي

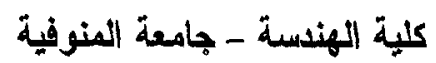

ملخصص البحث

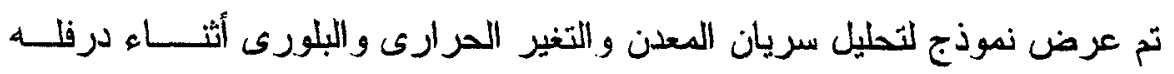

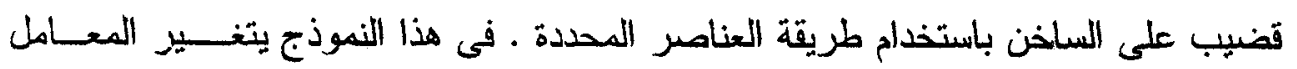

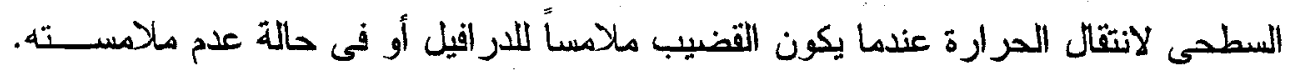

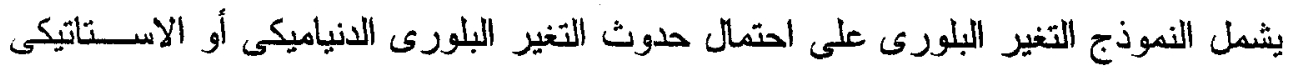

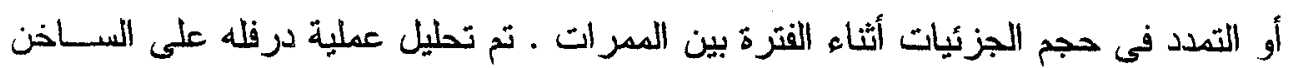

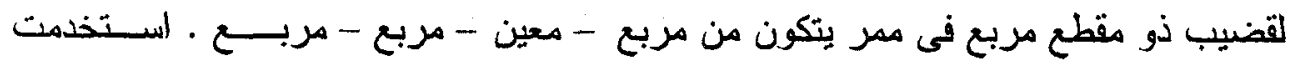

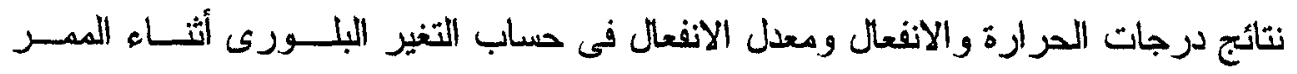

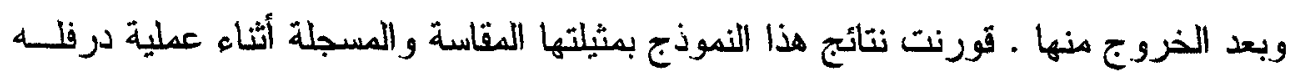
مشابهة فى المعل حيث أظهرت النتائج تطابق مناسب. 